\title{
Effect of Cu Additions on the Microstructure and Mechanical Properties of Spray Deposited Zn-30AI Alloy
}

\author{
Hong-Wei LIU a, ${ }^{\star}$, Feng WANG ${ }^{b}$, Shu-Hui HUANG, Hong-Wei YAN, Xi-Wu LI, \\ Zhi-Hui LI, Yong-An ZHANG and Bai-Qing XIONG
}

State Key Laboratory for Nonferrous Metals and Process, General Research Institute for Nonferrous Metals, Beijing 100088, China

aEmail: Ihw@grinm.com. ${ }^{\mathrm{b}}$ Email: wfbs@263.net

Keywords: Microstructure, Mechanical properties, Spray deposition, Zn-Al alloy.

\begin{abstract}
Zn}-30 \mathrm{Al}-\mathrm{xCu}(\mathrm{x}=0,1,2,4)$ alloys were prepared by the spray atomization and deposition technique. The microstructures of the spray-deposited alloys were investigated by means of scanning electron microscope, transmission electron microscope, X-ray diffraction. The results indicate that the $1 \mathrm{wt}$. \% $\mathrm{Cu}$ addition to spray-deposited Zn-30Al alloy does not make significant change in microstructure. However, with the 2, 4 wt. \% Cu additions to the alloy, some $\varepsilon$-CuZn 4 compounds with particle or irregular shapes were observed on the grain boundaries in the microstructures. Tensile test results confirmed that the $1 \mathrm{wt}$. \% Cu addition displays superior tensile strengths, whereas the 2, 4 wt. \% Cu additions led to the decreasing of the improvement effect of the tensile strengths.
\end{abstract}

\section{Introduction}

$\mathrm{Zn}$-Al alloys have been found to be a promising energy and cost effective substitute to a certain extent plain bearings. Zn-Al alloys exhibit high specific strength, excellent wear resistance, good casting properties and lower coat compared to other nonferrous metals [1]. The addition of $\mathrm{Cu}$ to the eutectoid $\mathrm{Zn}-\mathrm{Al}$ alloys improves its mechanical properties, creep resistance and corrosion behavior [2,3]. In order to improve the mechanical properties of $\mathrm{Zn}-\mathrm{Al}$ alloys, various metallurgical processes, such as continuous casting, thermal evaporation and spray deposition etc. are developed[4,5]. It has been recognized generally that the spray deposited process is an innovative technique of rapid solidification. In this process, droplets are first atomized from a molten metal stream, quickly cooled by an inert gas, then deposited on a substrate, and finally built up to form a low-porosity deposit with the required shape[6,7].

In this work, one binary $\mathrm{Zn}-\mathrm{Al}$ and three ternary $\mathrm{Zn}-\mathrm{Al}-\mathrm{Cu}$ alloys were produced by the spray atomization and deposition technique. The objective of this study is to investigate the microstructural evolution and mechanical properties of spray-deposited $\mathrm{Zn}-30 \mathrm{Al}-\mathrm{xCu}(\mathrm{x}=0,1,2,4)$ alloys, and the effect of $\mathrm{Cu}$ addition on the microstructure and mechanical properties of spray-deposited $\mathrm{Zn}-\mathrm{Al}$ alloy was analyzed.

\section{Experimental Procedures}

In Table 1 are listed the chemical compositions of the $\mathrm{Zn}-\mathrm{Al}-\mathrm{Cu}$ alloys. The spray deposition experiments were conducted in an environmental chamber. During spray-deposition process, the molten metal was atomized by $\mathrm{N} 2$ at $700{ }^{\circ} \mathrm{C}$, the distance of atomizing deposition was kept constant at $500 \mathrm{~mm}$. The preform, after being cut into cylindrical billets was extruded at a temperature of $250{ }^{\circ} \mathrm{C}$ with a reduction ratio of $10: 1$ and a ram speed of $5 \mathrm{~mm} / \mathrm{s}$. After extrusion, the materials were cooled in air. The microstructures of spray-deposited materials were characterized using scanning electron microscopy (SEM) attached with energy dispersive X-ray analyses (EDX), transmission electron microscopy (TEM) and X-ray diffraction. A S360 type scanning electron microscopy working at $15 \mathrm{kV}$ was used to observe the microstructures. The scanning electron microscopy samples were prepared using standard metallographic techniques and were etched using Keller's reagent. The transmission electron microscopy studies were conducted on a H-800 type transmission 
electron microscope at an acceleration voltage of $200 \mathrm{kV}$. The X-ray diffraction experiments were performed on a Japan Rigaku diffractormeter using $\mathrm{Cu}-\mathrm{K} \alpha$ radiation. The tensile tests were conducted with an Instron tensile testing machine at an initial strain rate of $0.5 \mathrm{~s}^{-1}$.

Table 1 Chemical compositions of the alloys (mass\%)

\begin{tabular}{llll}
\hline Alloy & Al & $\mathrm{Cu}$ & Zn \\
\hline A0 & 30 & 0 & Bal. \\
A1 & 30 & 1 & Bal. \\
A2 & 30 & 2 & Bal. \\
A4 & 30 & 4 & Bal. \\
\hline
\end{tabular}

\section{Results and Discussion}

\section{Microstructure}

Fig.1 (a) shows the typical SEM microstructure of the spray-deposited A0 alloy, which is composed of the $\alpha$-Al matrix and the $\eta-Z n$ phase mostly with a lamellar shapes. The coarse and fine lamellar $\alpha-\mathrm{Al}+\eta-Z n$ eutectoid was primary phase in the microstructure. With the addition of $1 \mathrm{wt}$ \% $\mathrm{Cu}$ to the spray-deposited A0 alloy, no obvious change was observed in the micrograph, in Fig.1 (b). Fig.1 (c) and (d) show the SEM micrographs of spray-deposited A2 and A4 alloys, it can be seen that 2, 4 wt. \% $\mathrm{Cu}$ additions lead to the variation in the microstructures. Some compounds with particle or irregular shapes were observed on the grain boundaries, as labeled by arrows. Quantitative energy-dispersive spectroscopy analysis results indicate that the compounds mainly contain elements of $\mathrm{Zn}$ and $\mathrm{Cu}$.
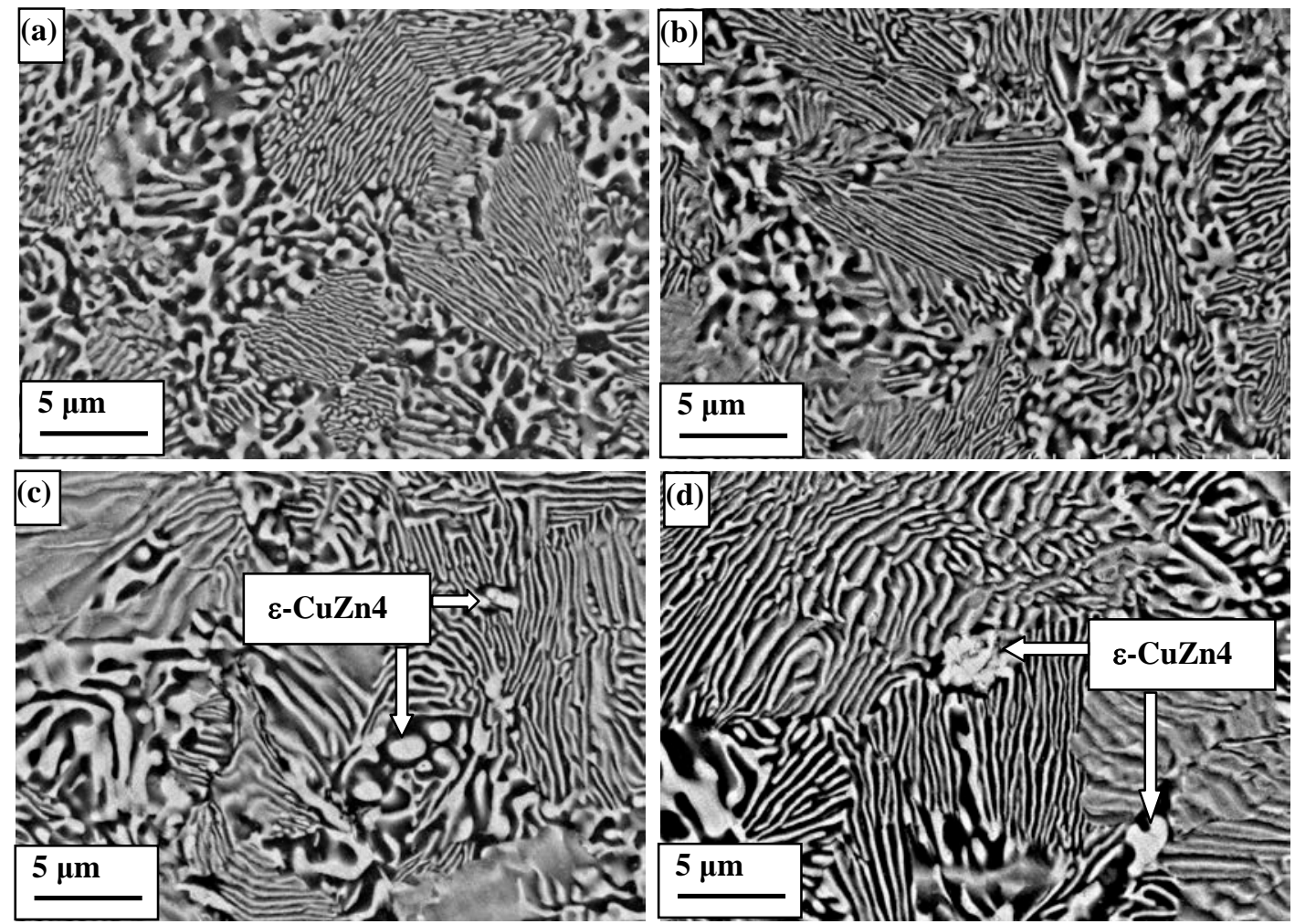

Fig.1 SEM micrographs of the spray-deposited alloys, (a) $A_{0}$; (b) $A_{1}$; (c) $A_{2}$; (d) $A_{4}$

Fig. 2 shows the X-ray diffraction (XRD) patterns of the spray-deposited alloys. XRD was performed to identify the phases in the microstructures, and analysis of the diffraction patterns shows that the compound phases mainly are $\varepsilon$-CuZn 4 in spray-deposited A2 and A4 alloys. No definitive evidence for the presence of $\varepsilon$-CuZn 4 was found in the XRD result of spray-deposited A1 alloy, this 
suggested that 1 wt. \% $\mathrm{Cu}$ addition was dissolved entirely into $\alpha$-Al or $\eta$-Zn phases under rapid solidification condition.

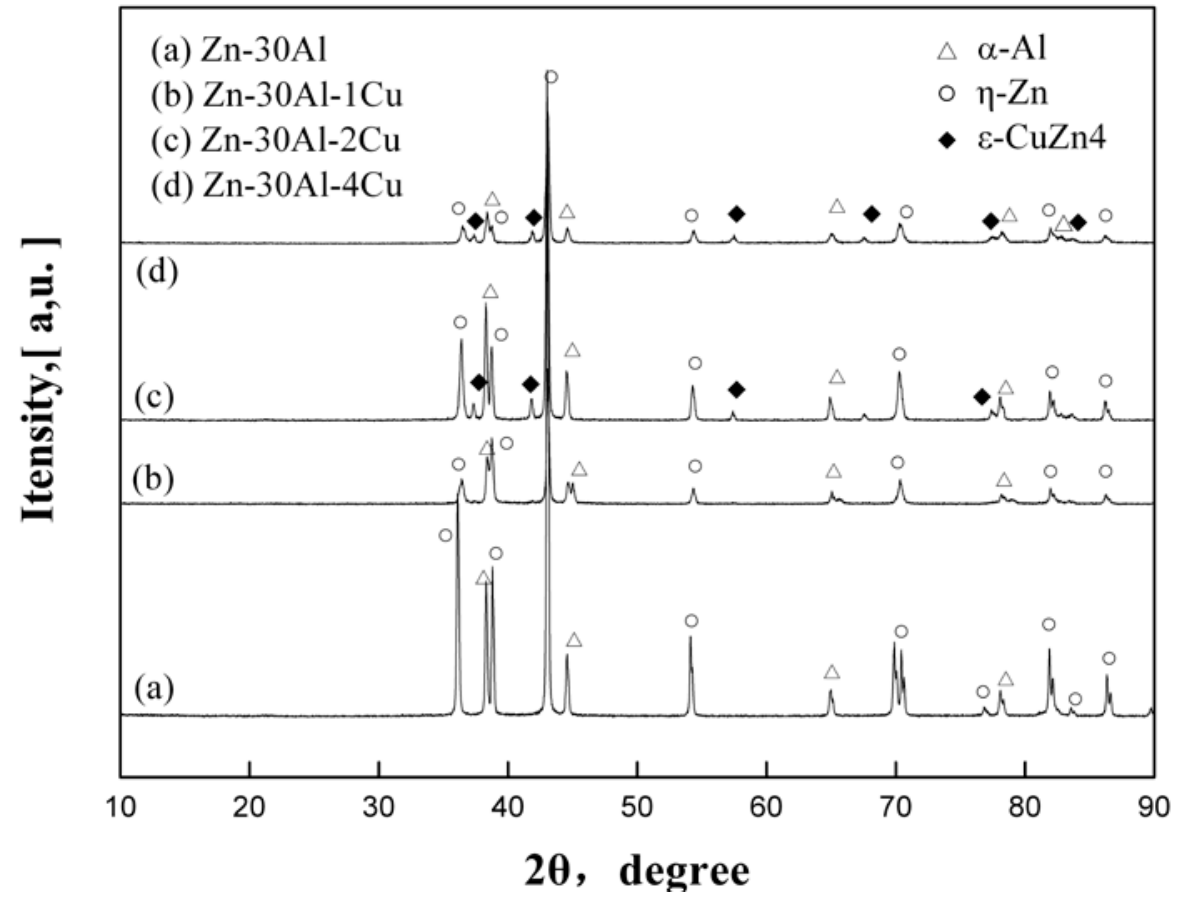

Fig.2 X-ray diffraction patterns of the spray-deposited alloys, (a) $A_{0}$; (b) $A_{1}$; (c) $A_{2}$; (d) $A_{4}$.

The lamellar structure eutectoid was primary phase in the microstructure of the spray-deposited alloys. Fig. 3(a) shows the typical TEM micrograph of the lamellar eutectoid, the selected area diffraction patterns of two phases of the eutectoid were indexed to be $\alpha$-Al and $\eta-Z n$, as can be seen in Fig. 3(b) and (c).
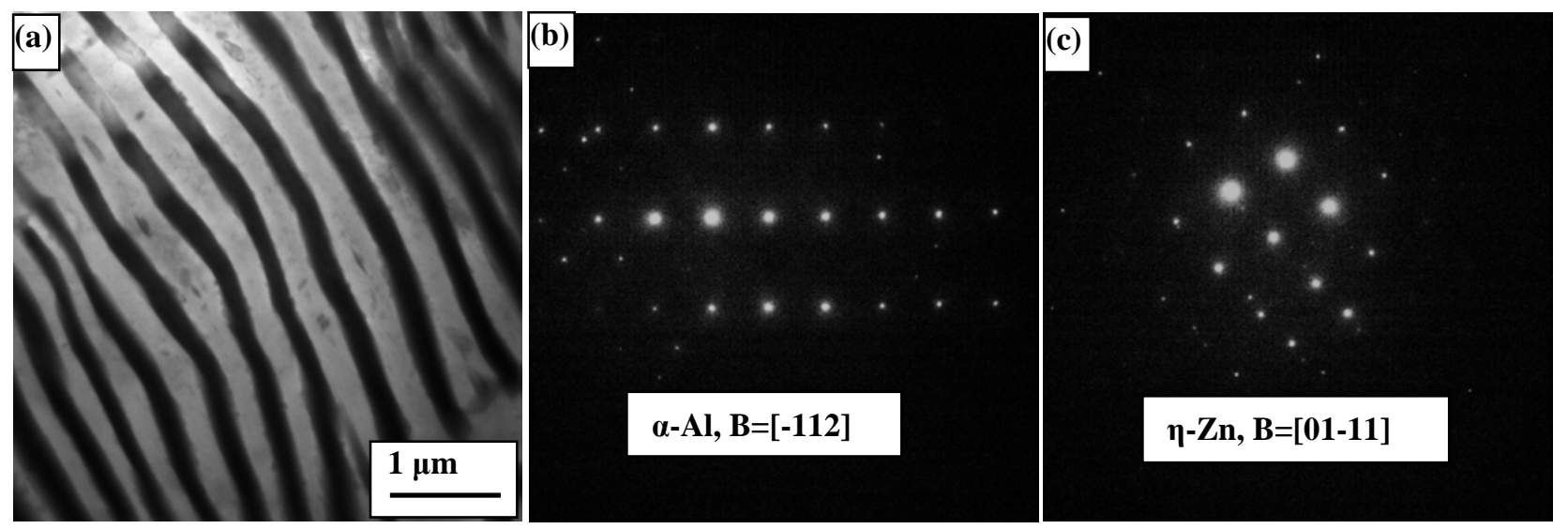

Fig.3 TEM micrographs showing the eutectoid phase ( $\alpha$-Al and $\eta-Z n)$ in the microstructure. (a) bright-field image; (b) (c) selected area diffraction patterns.

Fig. 4 shows the TEM micrographs of the particle-like compound phases on the grain boundaries in the microstructure of spray deposited $\mathrm{Zn}-30 \mathrm{Al}-4 \mathrm{Cu}$ alloy. Indexing of the selected area diffraction patterns indicates that the phase is $\varepsilon$-CuZn 4 compounds with hexagonal parameters of a $=0.274 \mathrm{~nm}$ and $\mathrm{c}=0.429 \mathrm{~nm}$ using electron diffraction, as can be seen in Fig. 4(b). The TEM result is in good agreement with the XRD ones, as shown in Fig. 2. 

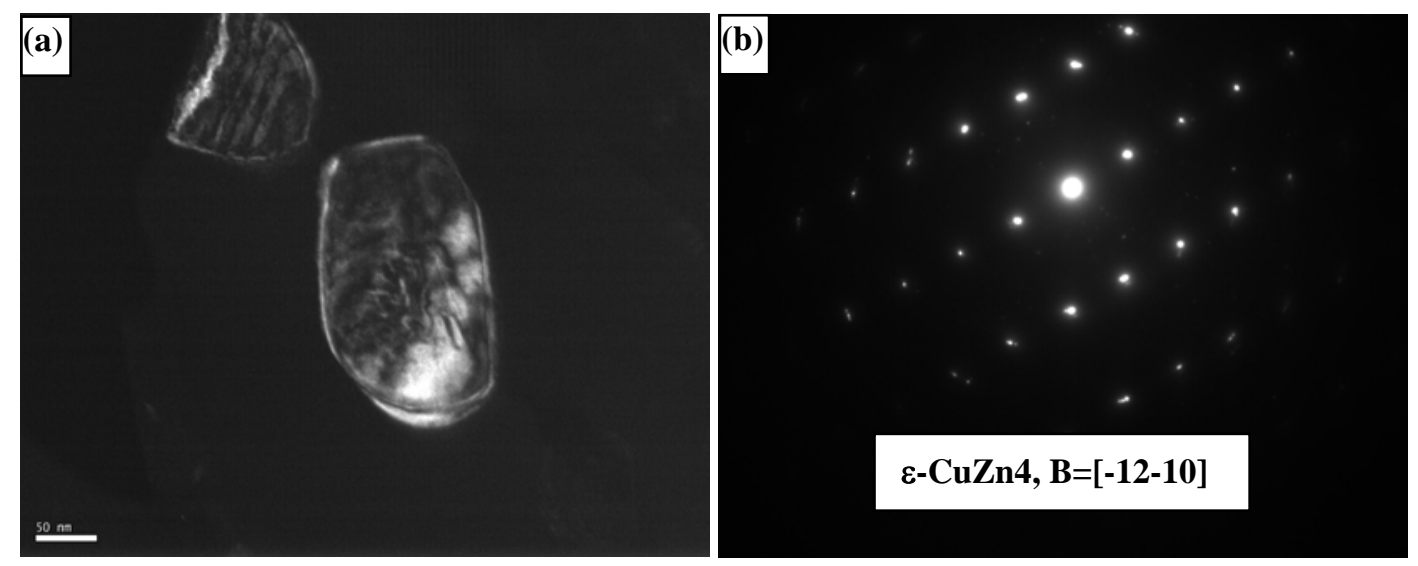

Fig.4 TEM micrographs of spray-deposited Zn-30Al-4Cu alloy, (a) dark-field image; (b) selected area diffraction pattern.

\section{Mechanical Properties}

Spray deposited $\mathrm{Zn}-\mathrm{Al}-\mathrm{Cu}$ alloys were subjected to tensile testing after hot extrusion. Table 2 summarized the tensile test results. It is worth noting that the tensile strengths of the A1, A2 and A4 alloys after extrusion are much higher than of the A0 alloy. Obviously, $\mathrm{Cu}$ addition leads to improvement of the tensile strengths. However, $1 \% \mathrm{Cu}$ addition leads to a substantial improvement of the tensile strengths, whereas $2 \%$ and $4 \% \mathrm{Cu}$ additions reduce the improvement effect of the tensile strengths due to the formation of $\varepsilon$-CuZn 4 compounds on the grain boundaries in the microstructures. It is worth nothing that the solution strengthening plays important role for the additional strengthening effects of the alloys. With $1 \% \mathrm{Cu}$ addition to the spray deposited $\mathrm{Zn}-30 \mathrm{Al}$ alloy, and $\mathrm{Cu}$ was dissolved entirely into $\alpha$-Al or -Zn phases due to the use of spray deposition technique, which provide much higher solubilities of the solute atoms. With 2 and $4 \% \mathrm{Cu}$ addition to the spray deposited $\mathrm{Zn}-30 \mathrm{Al}$ alloy, $\mathrm{Cu}$ atoms were dissolved partially into the $\alpha$ - $\mathrm{Al}$ or $-\mathrm{Zn}$ phases, and residual $\mathrm{Cu}$ addition was formed particle or irregular shaped $\varepsilon$-CuZn 4 compounds on the grain boundaries. Thus, the solution strengthening effect of the alloys was decreased, and tensile strengths of the A2 and A4 alloys are inferior to A1 alloy.

Table 2 Tensile properties of the spray-deposited Zn-Al-Cu alloys

\begin{tabular}{lllll}
\hline Alloy & Processing & $\begin{array}{l}\text { Ultimate tensile } \\
\text { strength }(\mathrm{MPa})\end{array}$ & $\begin{array}{l}\text { Yield strength } \\
(\mathrm{MPa})\end{array}$ & $\begin{array}{l}\text { Elongation } \\
(\%)\end{array}$ \\
\hline A0 & & 336 & 298 & 35.2 \\
A1 & Spray deposition + & 386 & 343 & 18.2 \\
A2 & extrusion & 369 & 329 & 24.1 \\
A4 & & 345 & 302 & 30.8 \\
\hline
\end{tabular}

\section{Summary}

The addition of $1 \% \mathrm{Cu}$ to spray deposited $\mathrm{Zn}-30 \mathrm{Al}$ alloy, no obvious change was observed in the microstructure. With additions of $2 \%$ and $4 \% \mathrm{Cu}$ to spray deposited $\mathrm{Zn}-30 \mathrm{Al}$ alloy, $\varepsilon$-CuZn 4 compounds with particle or irregular shapes were observed on the grain boundaries in the microstructures. The tensile test results indicate that the $1 \% \mathrm{Cu}$ addition to the alloy improves its tensile strengths significantly. In contrast, $2 \%$ and $4 \% \mathrm{Cu}$ additions reduce the improvement effect of the tensile strengths of the alloys.

\section{Acknowledgement}

This work was supported by the National Natural Science Foundation of China (No. 51271037). 


\section{References}

[1] Murat Aydin, Temel Savaskan: Mater. Inter. J. Fatigue. Vol. 26 (2004), p. 103

[2] Hector J. Dorantes-Rosales, Victor M. Lopez-Hirata, Jose L. Mendez-Velazquez, Maribel L. Saucedo-Munoz, David Hernandez-Silva: J. Alloy and compounds Vol.313(2000), p.154.

[3] Reza Mojaver, Hamid Reza Shahverdi: Wear Vol. 271(2011), p. 2899.

[4] Y. H. Zhu, W. B. Lee: Mater. Sci. Eng. A. Vol. 293(2000), p. 95.

[5] Yuwei Xun, Farghalli A. Mohamed: Mater. Sci. Eng. A. Vol. 432(2006), p. 261.

[6] P. Bai, X. Hou, X. Zhang, C. Zhao, Y. Xing: Mater. Sci. Eng. A Vol.508 (2009), p. 23.

[7] M.M. Sharma, M.F. Amateau, T.J. Eden, Acta Mater. Vol. 53 (2005), p. 2919. 